\title{
Processo para remoção de ácido sulfídrico de biogás
}

\section{Process of sulfidric acid removal from biogas}

\author{
Laercio Mantovani Frare \\ Engenheiro Químico pela Universidade Estadual de Maringá (UEM). Doutor em Engenharia Química pela UEM. \\ Professor do curso de Tecnologia em Gestão Ambiental da Universidade Tecnológica Federal do Paraná (UTFPR)

\section{Marcelino Luiz Gimenes} \\ Engenheiro Químico pela UEM. Doutor em Engenharia Química pela Universidade de Leeds. \\ Professor e Pesquisador do Departamento de Engenharia Química da UEM

\section{Nehemias Curvelo Pereira} \\ Químico Industrial pela Universidade Federal de Sergipe (UFS). Doutor em Engenharia Química pela Universidade \\ Federal do Rio de Janeiro (UFRJ). Professor e Pesquisador do Departamento de Engenharia Química da UEM
}

\section{Resumo}

No desenvolvimento deste trabalho foram realizados experimentos para determinar a redução do teor de $\mathrm{H}_{2} \mathrm{~S}$ de correntes de biogás por um processo de absorção com reação química em solução de Fe/EDTA de concentração igual a 0,4M. Os ensaios experimentais foram realizados a $25^{\circ} \mathrm{C}$ em um intervalo de vazões de solução catalítica, de 22 a 250 mL/min, e vazão de gás igual a 265 mL/min. Para essas condições, determinou-se a vazão ótima de líquido para atingir altas remoções de $\mathrm{H}_{2} \mathrm{~S}$ de biogás e analisou-se o crescimento de partículas de enxofre formadas durante a reação química. Utilizaram-se colunas de borbulhamento construídas em acrílico com 36,0 cm de altura e 5,0 cm de diâmetro interno. Os resultados obtidos permitem concluir que a razão ótima de contato entre gás e líquido para uma remoção eficiente de $\mathrm{H}_{2} \mathrm{~S}$ de correntes de biogás tratadas com soluções de Fe/EDTA deve ser maior do que 0,46.

Palavras-chave: biogás; ácido sulfídrico; absorção química; Fe/EDTA.

\begin{abstract}
In the development of this paper experiments were conducted to investigate the removal of $\mathrm{H}_{2} \mathrm{~S}$ from biogas stream by means of an absorption process with chemical reaction with a $0.4 \mathrm{M} \mathrm{Fe} /$ EDTA solution. Experimental tests were carried out at $25^{\circ} \mathrm{C}$ with an interval of catalytic solution from 22 to $250 \mathrm{~mL} / \mathrm{min}$, and gas outflow at $265 \mathrm{~mL} / \mathrm{min}$. For these conditions, it was determined the optimal value of liquid flowrate to reach high $\mathrm{H}_{2} \mathrm{~S}$ removals from biogas and it was analyzed the sulfur particle formed during chemical reaction. Bubbling columns made of plastic acrylic having $36.0 \mathrm{~cm}$ height and $5.0 \mathrm{~cm}$ internal diameter were used. The results showed that the optimal contacting ratio of gas to liquid flowrates for efficient removal of $\mathrm{H}_{2} \mathrm{~S}$ from biogas treated with Fe/EDTA solutions should be greater than 0.46 .
\end{abstract}

Keywords: biogas; sulfidric acid; chemical absorption; Fe/EDTA.

\section{Introdução}

O biogás tem origem nos efluentes dos setores agroindustrial, urbano (lodo das estações de tratamento dos efluentes domésticos) e ainda nos aterros de Resíduos Sólidos Urbanos (RSU) sendo resultado da degradação biológica anaeróbia da matéria orgânica contida nos resíduos. Esse gás é constituído, principalmente, por metano (50-70\%), gás carbônico (25-45\%) e pequenas quantidades de hidrogênio, nitrogênio e ácido sulfídrico $\left(\mathrm{H}_{2} \mathrm{~S}\right)$. O biogás possui um alto poder calorífico devido à grande quantidade de metano em sua composição, mas sua utilização torna-se limitada pela presença do ácido sulfídrico (PRICE; CHEREMISINOFF, 1995). Para o homem, o $\mathrm{H}_{2} \mathrm{~S}$ tem grande potencial irritante, agindo primeiramente nos olhos e nariz. A exposição severa a esse gás pode causar coma imediato com ou sem convulsão e até a morte. A exposição menos intensa geralmente causa tontura, fadiga, náusea, tosse, diarreia, perda de apetite, irritação na pele, sensação de secura e dor no nariz e no peito, gastrite, dor de cabeça e danos neurológicos (PRICE; CHEREMISINOFF, 1995). Uma alternativa para que o biogás possa ser utilizado como combustível sem restrições devido aos problemas apresentados é a remoção do $\mathrm{H}_{2} \mathrm{~S}$ presente pelo processo da absorção com reação química.

O princípio da absorção baseia-se na transferência de um componente de uma mistura gasosa para um líquido absorvente, devido à solubilidade entre ambos e à diferença de concentração. Trata-se de 
fazer o gás passar ou ter contato com um líquido no qual seja solúvel. Quando num processo de absorção tem-se a ocorrência de uma reação química entre o gás absorvido fisicamente e o líquido solvente, podendo este líquido ser ou não regenerado, o processo é denominado absorção química. Difere de uma absorção física em que o gás absorvido é simplesmente dissolvido no solvente líquido (WELTY; WICKS; WILSON, 1984). Atualmente, existem alternativas acerca da absorção química estabelecidas na forma de processos industriais capazes de separar o $\mathrm{H}_{2} \mathrm{~S}$ de uma corrente gasosa pelo uso de metais quelados (KOHL; RIESENFELD, 1985).

\section{Remoção de $\mathrm{H}_{2} \mathrm{~S}$ do biogás com solução de Fe/EDTA}

A rota química utilizada no desenvolvimento deste trabalho teve como princípio o uso de metais quelados na remoção de $\mathrm{H}_{2} \mathrm{~S}$ pelo processo de absorção química. Segundo Wubs e Beenackers (1994) e Demmink e Beenackers (1998), a absorção do $\mathrm{H}_{2} \mathrm{~S}$ pode ser representada pelas reações químicas apresentadas nas Equações 1 e 2 .

$$
\begin{aligned}
& \mathrm{H}_{2} \mathrm{~S}_{\text {(g) }} \rightarrow \mathrm{H}_{2} \mathrm{~S}_{\text {(aq) }} \\
& \mathrm{H}_{2} \mathrm{~S}_{\text {(aq) }}+2 \mathrm{Fe}^{3+} / \mathrm{EDTA} \rightarrow \mathrm{S} \downarrow+2 \mathrm{H}^{+}+2 \mathrm{Fe}^{2+} / \mathrm{EDTA}
\end{aligned}
$$$$
\text { Equação } 1
$$

$\mathrm{Na}$ Equação 1 está representada a etapa onde ocorre a transferência de massa do componente a ser removido da fase gasosa para a fase líquida. Na Equação 2, o $\mathrm{H}_{2} \mathrm{~S}$ já na forma aquosa reage com a solução de Fe/EDTA (Ferro/Ácido etilenodiaminotretraacético) e o enxofre é convertido para a forma insolúvel. O elemento ferro, inicialmente com carga +3 , é levado a uma carga igual a +2 , ou seja, é reduzido e se torna inativo. O composto $\mathrm{Fe}^{+2} /$ EDTA é regenerado e o elemento ferro é convertido em forma férrica pela oxidação da solução com oxigênio de acordo com as reações apresentadas nas Equações 3 e 4:

$$
\mathrm{O}_{2(\mathrm{~g})} \rightarrow \mathrm{O}_{2(\mathrm{aq})}
$$

$\mathrm{O}_{2(\text { aq) }}+4 \mathrm{Fe}^{+2} / \mathrm{EDTA}+2 \mathrm{H}_{2} \mathrm{O} \rightarrow 4 \mathrm{Fe}^{3+} / \mathrm{EDTA}+4 \mathrm{OH}$

Equação 4

Assim, o quelato de ferro (Fe/EDTA) pode ser considerado um pseudocatalisador na reação do $\mathrm{H}_{2} \mathrm{~S}$ com o oxigênio. $\mathrm{O}$ enxofre produzido é facilmente recolhido e pode ser comercializado. A reação

Tabela 1 - Composição aproximada do biogás sintético

$\begin{array}{lc}\text { Gases } & \begin{array}{c}\text { Mistura sintética } \\ \text { (\% em volume) }\end{array} \\ \mathrm{CH}_{4} & 79,78 \\ \mathrm{CO}_{2} & 14,13 \\ \mathrm{H}_{2} \mathrm{~S} & 2,42 \\ \mathrm{~N}_{2}+\mathrm{O}_{2} & 3,67\end{array}$

global que representa o processo de purificação pode ser ilustrada pela Equação 5 .

$\mathrm{H}_{2} \mathrm{~S}_{(\mathrm{g})}+1 / 2 \mathrm{O}_{2(\mathrm{~g})} \rightarrow \mathrm{S}_{(\mathrm{s})}+\mathrm{H}_{2} \mathrm{O}_{(\mathrm{l})}$ Equação 5

A escolha desse processo de purificação levou em consideração as vantagens que proporciona, tais quais: elevada eficiência de remoção de $\mathrm{H}_{2} \mathrm{~S}$; seletividade na remoção do $\mathrm{H}_{2} \mathrm{~S}$, evitando-se gasto desnecessário de reagentes; as condições ambientes são favoráveis ao processo; a solução catalítica Fe/EDTA é facilmente regenerada; e a absorção química do $\mathrm{H}_{2} \mathrm{~S}$ traz como produto final o enxofre elementar, produto estável, de fácil comercialização e que pode ser disposto em aterro industrial com menor potencial poluente.

\section{Metodologia}

Neste item são apresentados os procedimentos adotados para caracterizar o sistema experimental de purificação de biogás em escala de bancada para a obtenção de parâmetros operacionais necessários para o dimensionamento de plantas em escala piloto.

\section{Biogás}

O biogás utilizado nos experimentos era uma mistura sintética com composição semelhante à de uma amostra típica proveniente de um biodigestor tipo UASB (Upflow Anaerobic Sludge Blanket) da indústria Gelita, unidade Maringá (PR). A Tabela 1 apresenta a composição aproximada do biogás sintético (fornecido pela White Martins Gases Industriais) utilizado neste trabalho.

\section{Características e preparo da solução de Fe/EDTA utilizada}

Durante todas as corridas experimentais, foram utilizadas as soluções de Fe/EDTA preparadas de acordo com as etapas descritas a seguir: foram pesadas $74,44 \mathrm{~g}$ do reagente EDTA (ácido etilenodiaminotetraacético) seco em estufa e posteriormente dissolvido em 1 L de água ultrapura. Em seguida, preparou-se uma solução padrão de zinco, dissolvendo 6,537 g de pastilhas de zinco em HCl. Essa solução foi dissolvida em $1 \mathrm{~L}$ de água ultrapura. A determinação da concentração da solução de EDTA foi feita por titulação da solução de zinco com a presença do indicador Erio-T. A solução de zinco foi titulada com a solução de EDTA até que a coloração da solução de zinco mudasse de vermelha para azul. Para a preparação do sal de ferro II, fez-se reagir 4,00 gramas de ferro (Fe) em pó com $60 \mathrm{~mL}$ de $\operatorname{HBr}(98 \%)$ até que todo o ferro tivesse reagido. A montagem exigiu um sistema fechado em atmosfera de argônio devido à grande instabilidade do $\mathrm{FeBr}_{2}$. Depois de completada a reação, a solução de $\mathrm{FeBr}_{2} / \mathrm{HBr}$ foi filtrada a vácuo e o sal foi imediatamente colocado 
para secar. A preparação da solução de Fe/EDTA foi realizada da seguinte forma: pesou-se 6,068 g de $\mathrm{FeBr}_{2}$, mantido em atmosfera inerte. $\mathrm{O}$ pH da solução de EDTA foi previamente ajustado a 9,5 com o auxílio de uma solução de $\mathrm{NaOH}$ igual a 4,0 M. O sal FeBr foi adicionado à solução de EDTA e diluído a $900 \mathrm{~mL}$. Ainda em atmosfera inerte, o pH da solução de Fe/EDTA foi ajustado a 7,5 (com $\mathrm{NaOH} 4,0 \mathrm{M}$ ) e então a solução foi diluída a $1 \mathrm{~L}$, utilizando água ultrapura (HORIKAWA, 2001).

Nas condições de preparação descritas, obteve-se por fim a solução de Fe/EDTA com concentração de 0,2 mol/L, cuja razão de ferro por agente quelante é 1,06. Essa solução teve, posteriormente, a sua concentração duplicada pela redução do volume de solvente.

\section{Descrição do funcionamento do sistema experimental}

A Figura 1 ilustra o sistema experimental utilizado para a realização dos experimentos. Este módulo encontra-se instalado no Departamento de Engenharia Química, bloco D-90, na Universidade Estadual de Maringá (PR).

A etapa de absorção com reação química para a remoção do ácido sulfídrico ocorria na coluna T-101 onde o biogás sintético alimentado reagia com a solução de $\mathrm{Fe}^{3+} / \mathrm{EDTA}$ devido ao contato das correntes em fluxo. Tanto a corrente de biogás (corrente 1) quanto a de solução reagente (corrente 4) tinham as suas vazões controladas pelas válvulas e quantificadas pelos rotâmetros R-101 e R-201, respectivamente. Para realizar a solubilização do biogás na fase líquida, foi instalado um dispersor de gás na base da coluna T-101. O dispersor da coluna T-101 possuía forma espiral e furos de 0,5 mm espaçados por 2,0 $\mathrm{mm}$ para que as bolhas produzidas fossem uniformes.

Após o processo reacional, no topo da coluna T-101 era obtido o biogás tratado sem a presença de ácido sulfídrico (corrente 5) e, na base da coluna, a solução de Fe $e^{2+} /$ EDTA (corrente 2) que deveria ser regenerada para que pudesse ser novamente utilizada. A corrente de biogás tratado ainda sofria uma absorção com água em uma coluna (T-301) recheada com anéis de Rasching antes de ser lançada para a atmosfera. A coluna T-301 era de vidro e possuía $96 \mathrm{~cm}$ de comprimento com 5,0 cm de diâmetro interno com o recheio composto por anéis de Rasching de vidro com $1,5 \mathrm{~cm}$ de altura por 1,0 cm de diâmetro. Esse procedimento foi implantado para se evitarem emissões de ácido sulfídrico proveniente dos ensaios experimentais em que, devido às condições operacionais testadas, a eficiência de remoção era reduzida. A corrente de solução contendo $\mathrm{Fe}^{2+} / \mathrm{EDTA}$ era enviada para a coluna T-201 onde passava pelo processo de regeneração, pelo contato em contracorrente, com ar atmosférico proveniente de um compressor. Na base da coluna T-201 também foi instalado um dispersor com as mesmas características do dispersor da coluna T-101 para realizar a dispersão do ar atmosférico na solução.
$\mathrm{O}$ recalque das soluções $\mathrm{Fe}^{3+} /$ EDTA e $\mathrm{Fe}^{2+}$ /EDTA contidas nas correntes 2 e 4 era realizado com o auxílio das bombas peristálticas P-101 e P-201, modelo 7553-70 MasterFlex - Cole-Parmer (6-600 RPM) através de mangueiras de silicone, respectivamente. As colunas T-101 e T-201 foram construídas em acrílico para permitir a visualização do contato gás-líquido, possuindo um diâmetro interno de $5 \mathrm{~cm}$ e uma altura total de $36 \mathrm{~cm}$.

Os valores da concentração de $\mathrm{H}_{2} \mathrm{~S}$, bem como dos demais gases, foram obtidos por cromatografia gasosa com a utilização de um cromatógrafo modelo Thermo Quest 2000, com coluna Porapak Q. Essas amostragens eram realizadas com o auxílio de seringas em um determinado ponto localizado na corrente 5 na saída da coluna T-101. Em todas as análises cromatográficas do biogás durante a realização dos experimentos, os componentes $\mathrm{N}_{2}$ (nitrogênio) e $\mathrm{O}_{2}$ (oxigênio) foram considerados conjuntamente, devido à dificuldade da identificação destes. Para evitar erros devido a contaminações ou resíduos de ensaios anteriores, as seringas eram previamente lavadas com o gás de amostragem e mantidas hermeticamente vedadas até a injeção no cromatógrafo.

\section{Determinação de condições operacionais}

Durante os ensaios experimentais, determinou-se a razão ótima de líquido (solução de Fe/EDTA alimentado na corrente 4, representado por L) e gás (biogás alimentado na corrente 1, representado por $G$ ) denominada de $L / G$ para se obter a máxima remoção do $H_{2} S$ presente no biogás. Essa razão é importante para que ao se modificar a vazão de alimentação de biogás de acordo com o processo de produção, também sejam alteradas as condições operacionais do sistema de purificação, ou seja, a vazão de solução em contracorrente na torre de absorção para não alterar a eficiência de remoção do $\mathrm{H}_{2} \mathrm{~S}$.

Além da razão $L / G$, outra determinação importante envolve o enxofre sólido produzido pela reação química, pois é preciso que seja removido continuamente para não influenciar o processo reacional

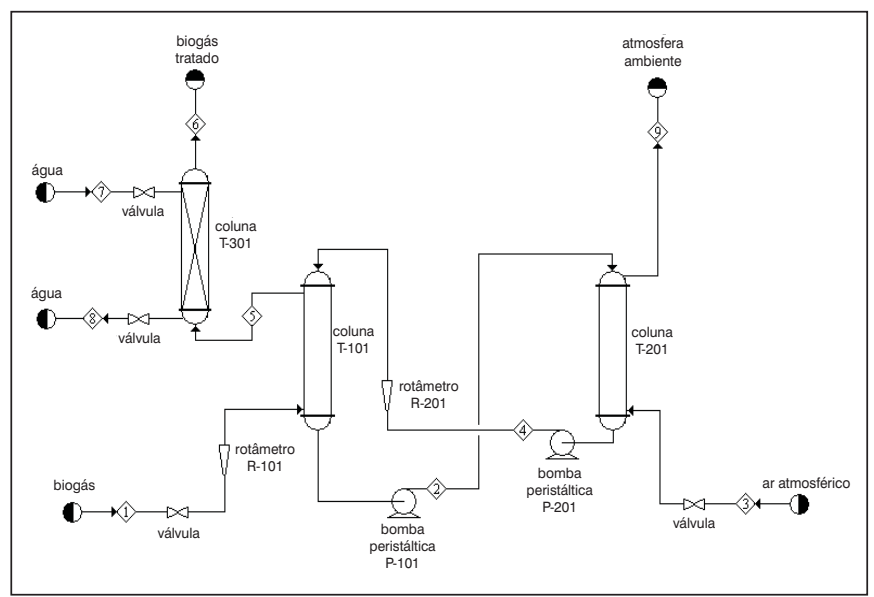

Figura 1 - Diagrama do sistema experimental utilizado nos testes de remoção de ácido sulfídrico de biogás com solução de Fe/EDTA 
diminuindo a eficiência de remoção do $\mathrm{H}_{2} \mathrm{~S}$. Para isso, determinou-se a distribuição do tamanho de partículas de enxofre ao longo do tempo para encontrar o tamanho médio das partículas.

\section{Determinação da razão ótima de líquido/gás (L/G)}

Na realização das corridas experimentais para a determinação da razão ótima de contato entre a solução catalítica de Fe/EDTA (L) e o biogás (G), as vazões utilizadas e parte do sistema experimental foram ilustradas na Figura 2. Durante os ensaios, a vazão de entrada de biogás foi ajustada para $265 \mathrm{~mL} / \mathrm{min}$ e a vazão de alimentação da solução de Fe/EDTA foram alteradas entre aos valores de 22 a $250 \mathrm{~mL} / \mathrm{min}$, obtendo-se assim razões entre 0,08 e 0,94, respectivamente. Ajustava-se também, antes do início de cada ensaio, a altura da coluna de líquido no interior da torre de absorção T-101 para que fosse sempre igual. As demais condições operacionais são apresentadas na Tabela 2.

Dessa forma, depois de ajustada a vazão de solução a passar pelo sistema e estabilizada a altura da coluna de líquido, iniciava-se a injeção de biogás com vazão constante e monitorava-se a eficiência do processo de remoção de ácido sulfídrico por amostragem dos gases de saída pelo topo da coluna T-101 na corrente 5. Nas corridas em

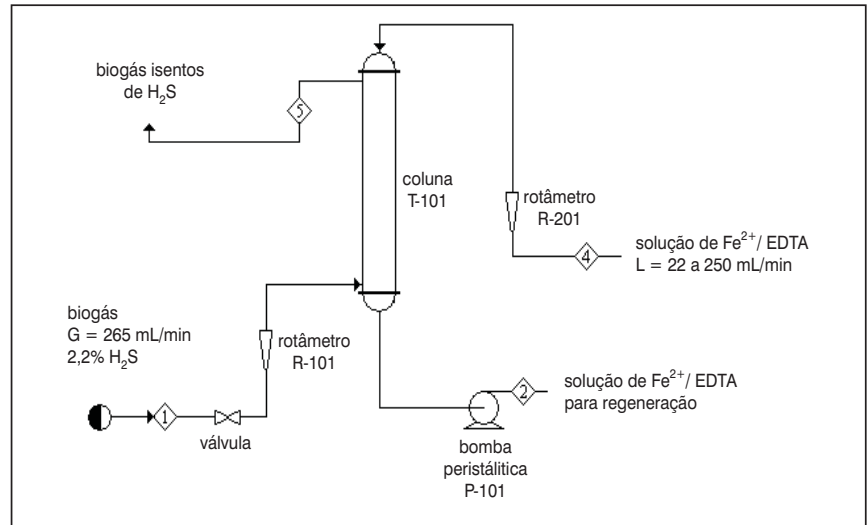

Figura 2 - llustração das condições operacionais utilizadas para a determinação da razão ótima de $L / G$

Tabela 2 - Condições especificadas para os testes experimentais para determinação da razão ótima de $\mathrm{L} / \mathrm{G}$

\begin{tabular}{lc}
\hline Vazão de biogás, $G(\mathrm{~mL} / \mathrm{min})$ & 265 \\
Vazão de solução, $\mathrm{L}(\mathrm{mL} / \mathrm{min})$ & 22 a 250 \\
Concentração da solução Fe/ & \\
EDTA (M) & 0,4 \\
Pressão do biogás (kPa) & 200 \\
Temperatura (o- $)$ & $\approx 25$ \\
\hline
\end{tabular}

Tabela 3 - Condições experimentais durante 0 estudo do crescimento das partículas de enxofre

\begin{tabular}{ccccc}
$\mathrm{G}$ & $\mathrm{L}$ & $\mathrm{T}$ & $\mathrm{P}$ & $\mathrm{C}$ \\
$(\mathrm{mL} / \mathrm{min})$ & $(\mathrm{mL} / \mathrm{min})$ & $\left({ }^{\circ} \mathrm{C}\right)$ & $(\mathrm{Psi})$ & $(\mathrm{M})$ \\
265 & 250 & 25 & 20 & 0,4 \\
\hline
\end{tabular}

que se detectava a presença de ácido sulfídrico na saída dos gases, o processo era interrompido, pois isso demonstrava que a razão estava abaixo da ótima e tinha ocorrido a desativação da solução de Fe/EDTA. Sendo assim, a solução de Fe/EDTA era regenerada na coluna T-201 com a injeção de ar atmosférico.

\section{Distribuição do tamanho das partículas de enxofre}

Os ensaios relativos à formação e ao crescimento das partículas de enxofre foram realizados com o equipamento operando em bateladas de dez horas. Os resultados foram analisados em decorrência do tempo de operação, sendo a distribuição do tamanho das partículas de enxofre acompanhadas em intervalos de duas horas. Após a realização de cada ensaio de duas horas, as partículas de enxofre elementares obtidas no processo de remoção do $\mathrm{H}_{2} \mathrm{~S}$ e recolhidas por filtração da solução de Fe/EDTA, eram redispersas utilizando-se água destilada e preparavam-se várias amostras em lâminas. As amostras foram observadas e analisadas através de microscopia ótica. A partir das fotos obtidas, as partículas de enxofre foram medidas e contadas a fim de se conhecerem as dimensões e sua distribuição por tamanho. Essa distribuição de tamanho das partículas foi obtida com auxílio de um microscópio (Olympus - BX50) acoplado a uma câmera digital (3CCD - Pró-series) e utilizando um software para a contagem (Image Pró Plus 4.1).

As corridas em batelada foram realizadas de maneira que todo o enxofre gerado durante a reação continuasse na mesma solução. Ou seja, a solução era utilizada em um teste, regenerada e novamente utilizada em outra corrida experimental, mas sem a completa remoção das partículas de enxofre.

As condições em que foram realizados os ensaios relativos às vazões e concentração da solução de Fe/EDTA, bem como a temperatura e a pressão do sistema são apresentadas na Tabela 3.

\section{Resultados e discussão}

Os ensaios experimentais foram conduzidos com o objetivo de subsidiar futuros dimensionamentos de sistemas de purificação de biogás em escala piloto utilizando-se a tecnologia apresentada.

\section{Resultados obtidos sobre a influência da razão ótima de líquido/gás (L/G) na eficiência de remoção de $\mathrm{H}_{2} \mathrm{~S}$ do biogás}

Na Figura 3 são apresentados os resultados das corridas experimentais para as vazões da solução de Fe/EDTA de 22 a $250 \mathrm{~mL} / \mathrm{min}$ para a vazão constante de $265 \mathrm{~mL} / \mathrm{min}$ de biogás. 
Paras as primeiras determinações experimentais (corridas $1 \mathrm{e}$ 2), a vazão de solução utilizada foi de 22 e $48 \mathrm{~mL} / \mathrm{min}$, respectivamente, e observou-se a presença de ácido sulfídrico após aproximadamente 15 minutos de experimento. Isso evidenciou uma rápida desativação da solução, mostrando que uma maior razão de líquido em relação à de biogás deveria ser ajustada para permitir a troca do volume de Fe/EDTA proveniente da coluna de regeneração. Foram realizadas, então, as corridas 3, 4 e 5 com as vazões de 61, 70 e 80 mL/min e o tempo para a detecção de ácido sulfídrico foi de aproximadamente $35 \mathrm{~min}$. Entretanto, com a realização do corrida 6 , a presença de ácido sulfídrico não foi detectada durante todo o tempo em que se monitorou a saída de biogás no experimento. Constatou-se que a vazão de $122 \mathrm{~mL} / \mathrm{min}$ permitiu uma troca de volume de solução na coluna suficientemente rápida para que não ocorresse a desativação da solução catalítica. Para confirmar esse resultado, também foi realizada a corrida 7 a uma razão de 0,94 e foi confirmada a total remoção do ácido sulfídrico da corrente de biogás tratado.

\section{Resultados obtidos na determinação do crescimento de partículas de enxofre}

As distribuições de tamanho da análise do crescimento das partículas de enxofre para as amostras retiradas após a realização de cinco corridas experimentais (corridas 8 a 12) são apresentadas na Figura 4. Para a elaboração das curvas, utilizou-se a função densidade de probabilidade, conforme apresentado por Levine, Berenson e Stephan (2000) e de acordo com a Equação 6, para o cálculo da frequência em função do diâmetro das partículas (x) determinado pela contagem de partículas fotografadas em microscópio. As curvas de tamanho de partículas seguem a distribuição normal (N) com média populacional envolvendo as partículas amostradas, $\mu$ e desvio-padrão populacional, $\sigma$.

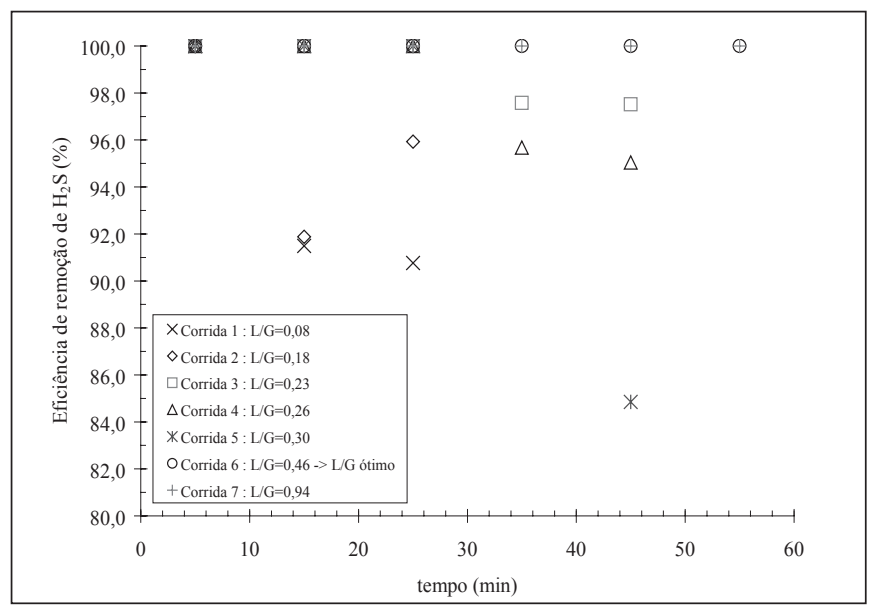

Figura 3 - Resultados experimentais para a determinação do valor ótimo de $L / G$ $f(x)=\frac{1}{\sigma \cdot \sqrt{2 \cdot \pi}} \cdot \exp \left[\frac{-(x-\mu)^{2}}{2 \cdot \sigma^{2}}\right]$

Equação 6

De acordo com os valores apresentados na Figura 4, foi observado que para a Corrida 8 , as partículas possuíam um diâmetro médio de 4,21 $\mu \mathrm{m}$ com um desvio-padrão de 2,51 $\mu \mathrm{m}$. Após o término da segunda corrida experimental de duas horas, o diâmetro médio das partículas presentes na amostra é igual a 5,63 $\mu \mathrm{m}$ com um desvio-padrão de 4,92 $\mu \mathrm{m}$. O mesmo aumento dos diâmetros médios pode ser observado para os outros testes. Entretanto, a área abaixo da curva é um exemplo da variação dos tamanhos de partículas evidenciado pelo aumento do desvio-padrão. Uma explicação para a forma das curvas pode ser a seguinte: a primeira curva apresenta um pequeno desvio-padrão porque no primeiro teste as partículas presentes se devem ao processo químico de formação, logo as partículas formadas apresentam, aproximadamente, o mesmo tamanho. Na segunda corrida, além das partículas formadas, também ocorre aglomeração, ou seja, duas ou mais partículas formam uma nova ainda maior. Dessa forma, temos as partículas isoladas formadas pela reação química e aquelas provenientes do processo de aglomeração. Sendo assim, o diâmetro médio aumenta, mas como ocorre uma variação grande dos tamanhos, aumenta também o desvio-padrão, ou seja, o desvio dos tamanhos em relação ao diâmetro médio.

O diâmetro médio obtido no processo em operação depois de um intervalo de dez horas foi igual a 10,63 $\mu \mathrm{m}$. Embora o valor do desvio padrão confirme a existência de partículas menores, o processo de remoção dessas partículas pode ser dimensionado para remover as de diâmetro igual ao apresentado.

As Figuras 5 e 6 apresentam duas imagens das partículas de enxofre presentes ao final de duas corridas experimentais obtidas por fotografia em microscópio. A Figura 5 representa as partículas referentes ao início dos ensaios experimentais e a Figura 6 representa as

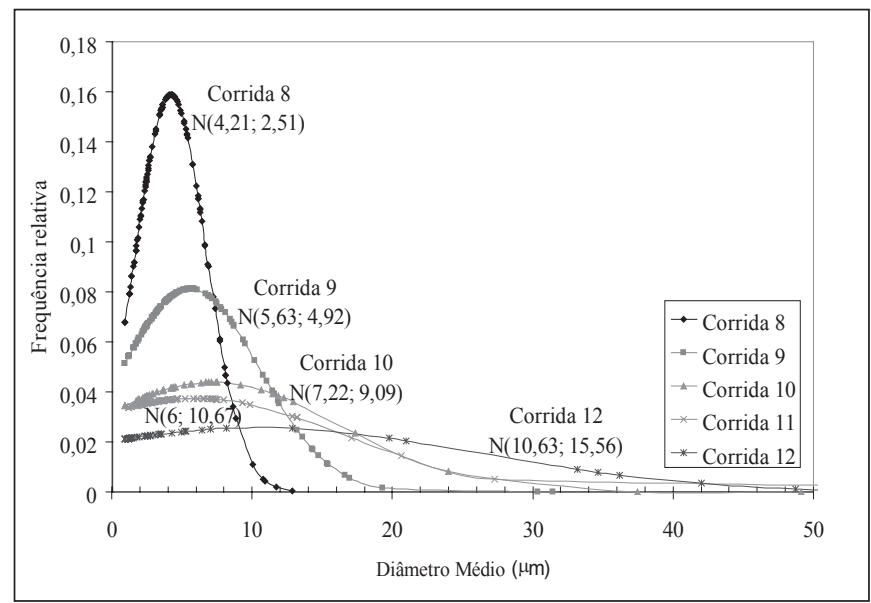

Figura 4 - Diâmetro médio das partículas para testes de remoção de ácido sulfídrico 


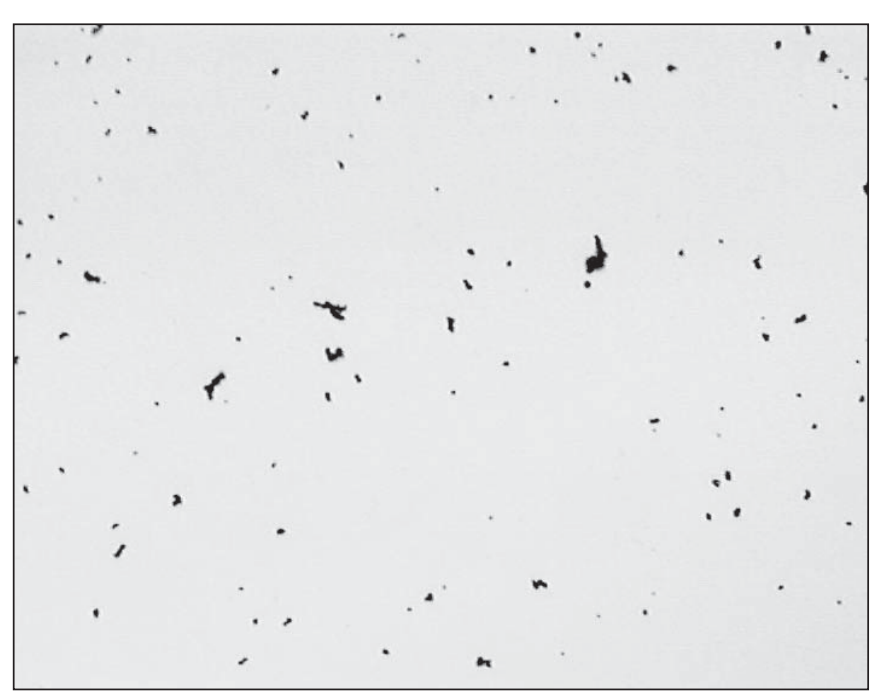

Figura 5 - Imagem de partículas de enxofre formadas no início dos ensaios experimentais

partículas referentes ao ensaio depois de dez horas de funcionamento. Ficam evidentes o aumento do tamanho de partículas por aglomeração e o alto valor da dispersão devido à presença de partículas formadas pelo processo reacional.

\section{Conclusões}

A partir dos dados experimentais obtidos, a razão ótima de $L / G$ para a total remoção do sulfeto de hidrogênio, respeitadas as concentrações do biogás e da solução de Fe/EDTA apresentadas, deve ser igual ou superior a 0,46. Dessa forma, valores inferiores a 0,46 conduzem a uma baixa eficiência de remoção causando rapidamente a desativação da solução catalítica, inviabilizando assim o processo e valores muito superiores a esse, próximos a 1,0, por exemplo,

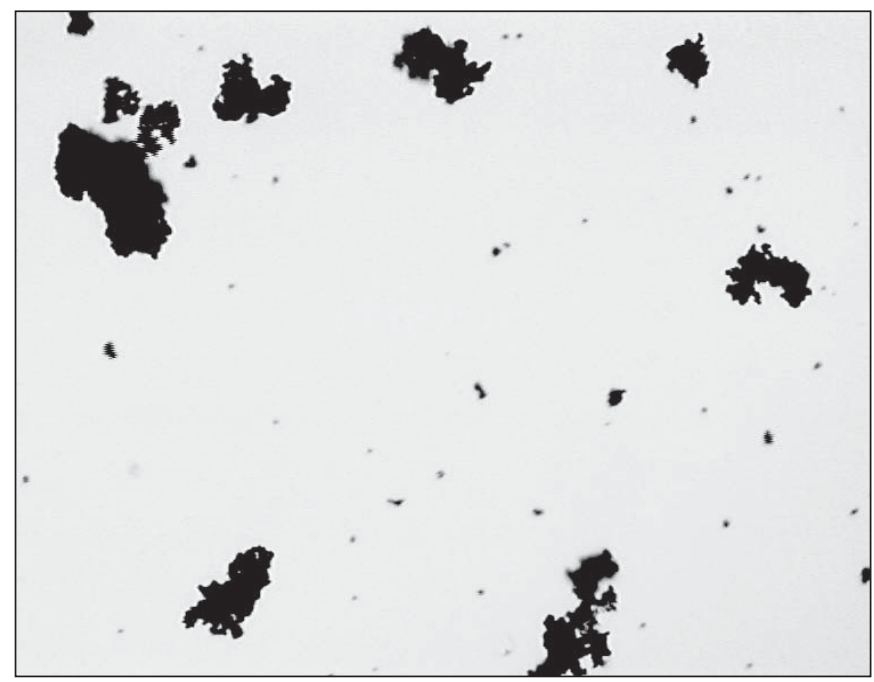

Figura 6 - Imagem de partículas de enxofre formadas após dez horas de ensaios experimentais

garantem a completa eficiência de remoção, mas aumentam os custos operacionais. Recomenda-se que na operação sejam utilizados valores com um incremento de 50\% sobre o valor ótimo encontrado.

A distribuição do tamanho de partículas demonstrou haver um crescimento das partículas de enxofre pelo processo de aglomeração durante a remoção de $\mathrm{H}_{2} \mathrm{~S}$, ocorrendo, assim, uma diminuição da eficiência de remoção do $\mathrm{H}_{2} \mathrm{~S}$ do biogás na presença de uma alta concentração de partículas de enxofre em suspensão na solução de Fe/EDTA. Dessa forma, o tempo ótimo de operação para se realizar a remoção das partículas de enxofre da solução de Fe/EDTA deve ser de no máximo 15 horas.

Dessa forma, unidades de purificação em escala piloto podem ser dimensionadas a partir de estudos de ampliação de escala e dos parâmetros operacionais apresentados.

\section{Referências}

DEMMINK, J.F., BEENACKERS, A.A.C.M. Gas desulfurization with ferric chelates of EDTA and HEDTA: new model for the oxidative absorption of hydrogen sulfide. Industrial and Engineering Chemistry Research, v. 37 , n. 4, p. 1444-1453, 1998.

HORIKAWA, M.S., Purificação de biogás: remoção de $H_{2} S$. Dissertação (Mestrado em Engenharia Química) - Departamento de Engenharia Química da UEM, Maringá, Paraná, 2001.

KOHL, A.L.; RIESENFELD, F.C. Gas purification. 4 ed. Houston: Gulf Publishing Company, 1985.
LEVINE, D.M.; BERENSON, M.L.; STEPHAN, D. Estatística: teoria e aplicações. Rio de Janeiro: Livros Técnicos e Científicos Editora, 2000.

PRICE, E.C.; CHEREMISINOFF, P.N. Biogas: production and utilization. New York: Ann Arbor Science, 1995.

WELTY, J.R.; WICKS, C.E.; WILSON, R.E. Fundamentals of momentum: heat and mass transfer. New York: John Wiley \& Sons, 1984.

WUBS, H.J.; BEENACKERS, A.A.C.M. Kinetics of $\mathrm{H}_{2} \mathrm{~S}$ absorption into aqueous ferric solutions of EDTA and HEDTA. AICHE Journal, v. 40, n. 3 , p. 433-444, 1994. 